***Accepted in Motivation Science***

Collaborative autonomy: The dynamic relations between personal goal autonomy and perceived autonomy support in emerging adulthood results in positive affect and goal progress

\author{
S. L. Levine ${ }^{1 *}$, A. C. Holding ${ }^{1}$, M. Milyavskaya ${ }^{2}$, \\ T. A. Powers ${ }^{3} \&$ R. Koestner ${ }^{1}$ \\ ${ }^{1}$ McGill University, Montreal, Canada \\ ${ }^{2}$ Carleton University, Ottawa, Canada \\ ${ }^{3}$ University of Massachusetts Dartmouth, New Bedford, USA
}

*Corresponding author:

Shelby L. Levine

2001 McGill College

Montreal, Quebec

H3A 1G1

Shelby.levine@mail.mcgill.ca

Date: September 2, 2020 


\begin{abstract}
Individuals are more successful when they pursue autonomous goals, but how do such goals develop in young adults? The current investigation suggests that the development of autonomous personal goals is a collaborative process. To test this, we examined whether autonomous motivation and autonomy support would interact in a dynamic reciprocal manner over the school year. A 5-wave longitudinal study was conducted with university students $(\mathrm{N}=$ 1544), who completed surveys on motivation, support, goal progress and affect. A dynamic reciprocal relation emerged between autonomous motivation and autonomy support. At each subsequent time-point, autonomy support led to increased autonomous motivation, and autonomous motivation led to increased autonomy support. This upward spiral of autonomous goal motivation and autonomy support also resulted in increased positive affect and goal progress over the academic year. These results suggest that the development of autonomous personal goals is a collaborative process fueled by an individual's personal autonomy and the interpersonal autonomy support they perceive from others, and this upward cycle is also beneficial for well-being and success. Future research is needed to determine how autonomously motivated individuals seek or elicit more autonomy support from others.
\end{abstract}

Keywords: Autonomous motivation, autonomy support, goals, positive affect, goal progress 
Collaborative autonomy: The dynamic relations between personal goal autonomy and perceived autonomy support in emerging adulthood results in positive affect and goal progress

Many university students start the school year by setting goals for themselves. Some students strive to get A's in all their classes, while others hope to make new friends or eat healthier. Independent of the specific goal, motivation is one factor that has been shown to consistently predict who will and who will not be successful during goal pursuit (Sheldon \& Houser-Marko, 2001; Sheldon \& Kasser, 1998). According to self-determination theory, motivation quality - the reasons for pursuing a goal - is especially relevant for predicting how successful an individual will be during goal pursuit. Individuals are thought to pursue goals for a multitude of reasons ranging from more controlled (because they feel like they have to) to more volitional/ autonomous (because they want to) (Ryan \& Deci, 2017). Autonomous goals are defined as reflecting personal interest, meaning, values, and enjoyment. For example, a student could be motivated to get good grades because they feel pressure from their parents (controlled) or because they take joy in learning, and education is a valued part of their identity (autonomous). There is a plethora of research on the benefits of autonomous goal motivation, but less research on how young adults may develop these autonomous personal goals. We propose that the development of autonomous personal goals is a collaborative process that is supported through the interplay of an individual's autonomy, and their perceived motivational support network.

\section{Autonomous Goals}

Pursuing goals for autonomous reasons appears to be highly adaptive. Autonomous goal motivation is defined pursuing one's goals for reasons that are personally meaningful and valued (identified), consistent with one's values and goals (integrated) and because pursuing this goal is 
enjoyable and satisfying (intrinsic) (Sheldon \& Elliot, 1999). Studies have consistently found that people make more progress over time on autonomously motivated goals than nonautonomous goals (Koestner, Otis, Powers, Pelletier \& Gagnon, 2008; Sheldon, 2014). This pattern of results was obtained for university students, working adults, and patients in treatment (Gorin, Powers, Koestner, Wing \& Raynor, 2014). There is also evidence from meta-analyses that greater goal progress translates into improved well-being (Koestner, Lekes, Powers \& Chicoine, 2002).

There are several mechanisms that appear to mediate the relation of autonomous motivation to greater goal success. Autonomy appears to optimize goal pursuit because it is associated with adaptive goal processes including subjective ease of pursuing the goal (Werner, Milyavskaya, Foxen-Craft \& Koestner, 2017), less goal conflict (Kelly, Mansell \& Wood, 2015), automatic shielding of goals from temptations and distractions (Milyavskaya, Inzlicht, Hope \& Koestner, 2015), fewer and less severe action crises (Holding, Hope, Harvey, Marion Jetten \& Koestner, 2017), malleable beliefs about one's self-control capacities (Sieber, Fluckiger, Mata, Bernecker \& Job, 2019), task-oriented coping (Gaudreau, Carraro \& Miranda, 2012), and more frequent and effective use of implementation plans (Koestner et al., 2002, 2008). Finally, when individuals pursue autonomous goals, they experience greater need satisfaction which promotes well-being (e.g. Kelly et al., 2015; Sheldon \& Elliot, 1999; Smith, Ntoumanis \& Duda, 2007).

\section{The Development of Autonomous Goals}

Given the benefits of autonomous goal motivation, it is important to examine how it develops. Autonomous motivation is often thought of as a self-initiated process in which one pursues personally meaningful goals in a volitional manner. However, a closer examination of the literature suggests that the development of autonomous goals is likely to be a collaborative 
process built around interpersonal relationships and shared goals. Consistent with the transactive model of goal pursuit, the development of personal goals occurs within our interpersonal environments (Fitzsimons \& Finkel, 2018). An individual's social environment can actively influence how they pursue their goals. For example, individuals are more likely to pursue autonomous goals in those environments that afford the satisfaction of the psychological needs of autonomy, competence, and relatedness, compared to environments where those needs are not satisfied (Milyaskaya, Nadolny \& Koestner, 2014). Additionally, there is an extensive literature which provides evidence that autonomy supportive goal environments are beneficial for the growth of autonomous motivation (see Su \& Reeve, 2011 or Vansteenkiste et al., 2012, for reviews). Autonomy support is defined as support which enhances one's volition or choice (Ryan \& Deci, 2000). Autonomy support for goals has recently been measured in terms of whether one feels that supporters listen to how you would like to do things and understand your perspective with respect to your goals (Koestner, Powers, Carbonneau, Milyavskaya \& Chua, 2012). Autonomy support has been used as a measure of how openly supportive one's motivational environment is.

Autonomy support is thought to establish the context for developing autonomous motivation, which is self-directed, personally meaningful, and pleasurable (Ryan \& Deci, 2017). Across various contexts, autonomy supportive teachers, parents, managers, peers, and partners have been shown to enhance autonomous motivation in others (e.g. Black \& Deci, 2000; Moreau \& Magneau, 2012; Patall et al., 2018; Soenens \& Vansteenkiste, 2005; Su \& Reeves, 2011). Heightened autonomy has, in turn, been related to greater goal progress, achievement, wellbeing, and relationship satisfaction (e.g. Bao \& Lam, 2008; Grolnick et al., 2014; Koestner, Ryan, Bernieri \& Holt, 1984). Self-determination theory acknowledges the benefits of supportive 
environments during goal pursuit, but to the best of our knowledge has yet to examine the reciprocal part of the transactive goal model. Individuals do not pursue goals in isolation and perceptions of support may influence their goal environment and pursuit.

\section{Reciprocal dynamic relations between autonomous goals and autonomy support.}

Although there is clear support for a causal relation from autonomy support to autonomous goal motivation, there has yet to be research which examines the reverse question, whether more autonomously motivated individuals seek out, perceive, or elicit more autonomy supportive relationships and social contexts. That autonomous goal motivation would lead individuals to seek environments which support their volition and avoid environments that are controlling is consistent with personality-environment fit theory, which posits that individuals select environments which fit their dispositional styles and also exert personal influence on their environments (Caplan, 1987). Psychological mechanisms may be deployed to reinforce preexisting traits or dispositions (McAdams, 2015). The autonomous student may select the autonomy supportive environment because they are attracted and responsive to this motivationcongruent support style (Roberts, Woods \& Caspi, 2008). By applying personality-environment fit theory to goal motivation, we can begin to understand how autonomously motivated individuals select and evoke autonomy supportive environments which suit their dispositional motivation. Over time, motivation and environmental support may continuously contribute to each other to result in a dynamic, reciprocal autonomous goal system, which may lead to subsequent achievement and well-being.

Both autonomous goal motivation and autonomy support are related to positive affectivity and well-being (e.g. Kelly et al., 2015; Gagne, 2003; Sheldon \& Elliot, 1999). This dynamic relationship between autonomous motivation and autonomy support may develop 
reciprocally through a positive reinforcement system. In line with the broaden and build theory, positive emotions experienced while acting autonomously or receiving autonomy support may lead one to continue to pursue autonomous action or autonomy support from others, which further fuels gains in positive emotions (Fredrickson, 2001). Thus, the reciprocal relation between autonomous motivation and autonomy support may be fueled through the positive emotions gained during this process. Positive and negative affect are separate constructs that can be examined independently (Diener \& Emmons, 1984). There is little evidence that autonomous goal motivation or support would contribute to negative affectivity, so this research focused on positive affect. Intrinsic motivation (i.e. goals pursued for personal enjoyment or pleasure) and autonomy supportive environments have indeed been found to interact synergistically to result in better performance outcomes (Vansteenkiste, Simons, Lens, Sheldon \& Deci, 2004). However, the synergistic nature of personal and interpersonal autonomy has yet to be explored longitudinally to determine whether this occurs in a dynamic cyclical manner over time. The reinforcing function of positive affect may partially explain why such a reciprocal relation would flourish in emerging adulthood.

\section{Present Investigation}

The current investigation consists of a multi-wave, longitudinal study of university students' goal pursuits in which autonomous motivation and autonomy support were repeatedly assessed over the span of a school year. Our aim was to examine whether the development of autonomous personal goals is a dynamic, collaborative process fueled by the interaction of personal autonomy, and perceived interpersonal support. We made use of the multi-wave, temporal nature of our data to establish whether there were dynamic and reciprocal relations between the personal and interpersonal forms of autonomy. Previous studies have shown that 
autonomy support enhances autonomous goal motivation, but no study has shown the reciprocal relation, nor has any study shown that the pattern would persist beyond one cycle of measurement. This research is a preliminary examination of whether autonomy flourishes in a dynamic manner. Specifically, we hypothesized that autonomy support is related to increased autonomous motivation (H1), and conversely that autonomous motivation is related to increased autonomy support over time $(\mathrm{H} 2)$. We also sought to determine whether the growth of autonomy is associated with positive affect and goal progress. We hypothesized that gains in both autonomous motivation and autonomy support would be associated with gains in goal progress (H3) and positive affect over the year $(\mathrm{H} 4)^{1}$. The hypotheses and analytical plan were posted on OSF before any analyses were conducted (but after data collection had occurred) ${ }^{2}$; they can be found along with all measures, data, and full outputs from analyses here: https://osf.io/ufhwz/?view_only=dc0df60a8bbd491e953935f2e7086939.

\section{Methods}

\section{Participants and Procedures}

Participants were 1544 students at a large Canadian University $\left(\mathrm{M}_{\mathrm{age}}=20.63, \mathrm{SD}_{\mathrm{age}}=\right.$ 3.08, 71.5\% female) collected over four years from 2015 to 2019. Participants were recruited through advertisements in classes and around campus to participate in a year-long study on goals. At the initial time point, participants were excluded if they did not complete ideographic information on their goals. The time points of the study were September, November, December,

\footnotetext{
${ }^{1}$ This hypothesis varied slightly from the preregistration as the researchers realized that the data could not actually address the initial question posed.

${ }^{2}$ Note initially this analysis was preregistered for a subset of the sample, but a final decision was made to go with the entire sample for a most robust finding after subsequent years were collected. Please see Appendix B on OSF for the original results with the subset of the original data. Additional analyses including goal progress were also added after preregistration in response to suggestions of the reviewers.
} 
February, and April. If participants completed each time-point they were compensated with $\$ 50$, if they completed a portion of the time points, they received partial compensation. Prior to taking part in the study, each participant was asked to read over and agree to the informed consent. In the initial assessment, all participants completed a series of demographic questions, as well as questions on mood and their motivation for personal goals. Participants were asked to set three goals for themselves for the academic year during the initial time point. Each year, at the secondand fourth-time points participants completed a measure on how supported they felt by others for their goals. In every year, at the third and fifth time points, participants completed the motivation measure again. At the final time point participants completed a survey on their mood and goal progress. The overall retention across the entire school year for all the subsamples was $84 \%$. Missing data was handled using FIML for structural equation models in MPlus. This research was approved by the university research and ethics board. A full list of our measures can be found on OSF under Appendix A.

\section{Measures}

Positive Affect. Positive affect at the first and final time points was assessed using 4items from Emmons (1992). Participants were asked to report how much they felt each emotion on a scale of 1 (Not at all) to 7 (Very). Emotional prompts included "Joyful", "Happy", "Pleased", and "Enjoyment/Fun". A mean of all items was taken to compute a positive affect score. $\alpha_{\mathrm{T} 1}=.85, \alpha_{\mathrm{T} 2}=.88$.

Goal Progress. Goal progress was assessed at the end-of-year. Participants rated how much they agreed with the following three statements: "I have made a lot of progress toward this goal", "I feel like I am on track with my goal plan" and "I feel like I am achieving this goal" (Koestner et al., 2012). Participants' responses were made on a 
7-point scale with 1 corresponding to strongly disagree and 7 corresponding to strongly

agree. Total goal progress was calculated as the mean of the end-of-year assessment items for all goals. $\alpha>.90$.

Autonomous Motivation. At time 1, 3 and 5 participants were asked about their motivation to pursue their goals using 3 items. For each goal, participants were asked to rate their motivation on a 7-point Likert-type scale, from 1 (not at all for this reason) to 7 (completely for this reason), on items that assessed identified, integrated and intrinsic reasons for goal pursuit (Sheldon \& Elliot, 1999). The prompt used to assess identified motives was "Because you really believe that it is an important goal to have - you endorse it freely and value it whole heartedly". The prompt used to assess integrated motives was "Because it represents who you are and reflects what you value most in life". The prompt used to assess intrinsic motives was "Because of the fun and enjoyment which the goal will provide you - the primary reason is simply your interest in the experience itself'. A summary measure of autonomous goal motivation was calculated as the mean of all identified, integrated, and intrinsic items for each of the individual's goals (Koestner et al., 2008). $\alpha_{\mathrm{T} 1}=.66, \alpha_{\mathrm{T} 3}=.72, \alpha_{\mathrm{T} 5}=.74$.

Autonomy Support. Perceived autonomy support was assessed for two supporters at Time 2 and 4 using three items which have been used to measure goal support in previous research (Koestner et al., 2002). First participants were asked to think of two people who have helped them while pursuing all their goals, and then they were asked a series of questions on how supportive each of these individuals have been. Examples of items include "I feel this person understands how I see things with respect to my goal" and "I am able to be open with this person about my goals". All ratings were made on a 7-point scale ranging from 1 (strongly disagree) to 7 (strongly agree). A mean of all items for each supporter was taken and then averaged to 
compute a perceived autonomy support score as a measure of how generally supportive their environment was. $\alpha_{\mathrm{T} 2}=.79, \alpha_{\mathrm{T} 4}=.78$.

\section{Analytical Plan}

First descriptive statistics were run. To determine change in affect over the year, residualized change scores were calculated using SPSS. To do this Time 5 positive affect was regressed on Time 1 positive affect and the unstandardized residual values were saved (Zumbo, 1999). Then, a fully unconstrained path model was built using MPlus Software (Muthen \& Muthen, 2015), as illustrated in Figure 1 below. To determine the best model fit with the greatest DFs, predictive pathways were constrained to the same value. First, the path between autonomous motivation and subsequent time points was constrained. Then, the path between received autonomy support and the subsequent time point was constrained. Following that the time-lagged paths were constrained. The purpose of constraining various pathways over time was to simplify and create the most parsimonious model. The best model was selected based on BIC, CFI, SRMR, RMSEA and $\chi^{2}$ values. The best model was used to determine indirect effects for the bidirectional mediation model. Using indirect effects, both bidirectional mediation models were tested (i.e. autonomous motivation $\rightarrow$ autonomy support $\rightarrow$ change in PA or goal progress and autonomy support $\rightarrow$ autonomous motivation $\rightarrow$ change in PA or goal progress). 


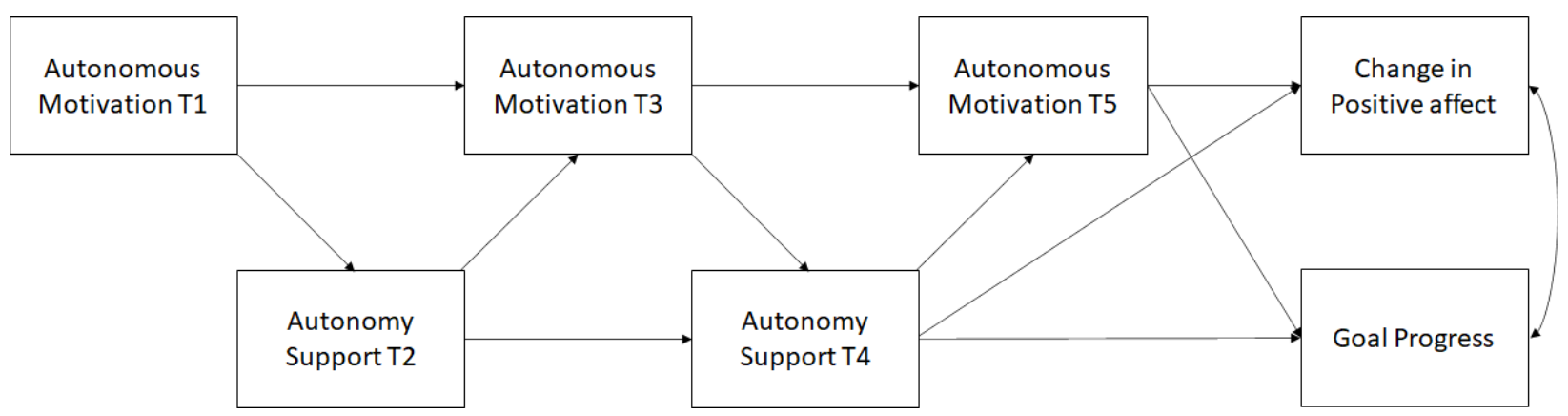

Figure 1. Theoretical path model of the path SEM to determine the reciprocal relation between autonomous support and autonomous motivation and the influence on goal progress and change in positive affect over the year.

\section{Results}

Descriptive Statistics. Below, Table 1 summarizes descriptive statistics for the variables of interest for the entire sample $(\mathrm{N}=1544)$ collected from $2015-2019$, as well as the correlation between these variables. The data set is included under Appendix C on OSF. 
Table 1

Means, standards deviation and correlations with 95\% CI between all variables of interest

\begin{tabular}{|c|c|c|c|c|c|c|c|c|}
\hline & $\mathrm{M}(\mathrm{SD})$ & T3AM & T5AM & T2AS & T4AS & T1PA & T5PA & T5GP \\
\hline T1AM & $5.27(.86)$ & $\begin{array}{c}.52 \\
{[.28, .56]}\end{array}$ & $\begin{array}{c}.42 \\
{[.37, .46]}\end{array}$ & $\begin{array}{c}.18 \\
{[.13, .23]}\end{array}$ & $\begin{array}{c}.15 \\
{[.10, .20]}\end{array}$ & $\begin{array}{c}.21 \\
{[.16, .25]}\end{array}$ & $\begin{array}{c}.13 \\
{[.07, .18]}\end{array}$ & $\begin{array}{c}.04 \\
{[-.01, .09]}\end{array}$ \\
\hline T3AM & $5.29(.87)$ & 1 & $\begin{array}{c}.55 \\
{[.51, .58]}\end{array}$ & $\begin{array}{c}.22 \\
{[.17, .27]}\end{array}$ & $\begin{array}{c}.18 \\
{[.12, .23]}\end{array}$ & $\begin{array}{c}.16 \\
{[.11, .21]}\end{array}$ & $\begin{array}{c}.14 \\
{[.08, .19]}\end{array}$ & $\begin{array}{c}.11 \\
{[.06, .17]}\end{array}$ \\
\hline T5AM & $5.37(.99)$ & - & 1 & $\begin{array}{c}.22 \\
{[.17, .28]}\end{array}$ & $\begin{array}{c}.19 \\
{[.14, .25]}\end{array}$ & $\begin{array}{c}.17 \\
{[.11, .22]}\end{array}$ & $\begin{array}{c}.17 \\
{[.11, .22]}\end{array}$ & $\begin{array}{c}.29 \\
{[.23, .33]}\end{array}$ \\
\hline T2AS & $5.83(.87)$ & - & - & 1 & $\begin{array}{c}.59 \\
{[.55, .62]}\end{array}$ & $\begin{array}{c}.17 \\
{[.12, .22]}\end{array}$ & $\begin{array}{c}.22 \\
{[.17, .27]}\end{array}$ & $\begin{array}{c}.18 \\
{[.12, .23]}\end{array}$ \\
\hline T4AS & $5.66(.97)$ & - & - & - & 1 & $\begin{array}{c}.13 \\
{[.08, .18]}\end{array}$ & $\begin{array}{c}.20 \\
{[.14, .25]}\end{array}$ & $\begin{array}{c}.20 \\
{[.15, .25]}\end{array}$ \\
\hline T1PA & $4.83(1.08)$ & - & - & - & - & 1 & $\begin{array}{c}.35 \\
{[.30, .40]}\end{array}$ & $\begin{array}{c}.11 \\
{[.06, .17]}\end{array}$ \\
\hline T5PA & $4.70(1.21)$ & - & - & - & - & - & 1 & $\begin{array}{c}.28 \\
{[.23, .33]}\end{array}$ \\
\hline T5GP & & - & - & - & - & - & - & 1 \\
\hline
\end{tabular}

Note: $\mathrm{AM}=$ autonomous motivation, $\mathrm{AS}=$ autonomy support, $\mathrm{PA}=$ positive affect and $\mathrm{GP}=$ goal progress. 
Upward Spiral Model. We used path analyses to test an upward spiral mechanism of autonomous motivation, autonomy support, goal progress and positive affect (as described in the analytical plan above). Appendix $\mathrm{C}$ on OSF reports how the model fit changed while constraining different pathways and how the final model was decided upon. The model with the best fit was fully unconstrained (Figure 2). This model had adequate fit: $\mathrm{BIC}=21525.76, \chi^{2}(9)$ $=71.24, \mathrm{p}<.001, \mathrm{CFI}=.967, \mathrm{RMSEA}=.068[.054 ; .083], \mathrm{SRMR}=.029$. Syntax and output are available in Appendix $\mathrm{C}$ on OSF. Please see Figure 2 for a representation of this model with statistics. Autonomous goal motivation predicted increased perceived autonomy support across the year. Additionally, autonomy goal support predicted increases in autonomous motivation throughout the school year. Both autonomous goal motivation and support predicted increased goal progress and positive affect over the year. Next, indirect effects were tested to determine whether a bi-directional mediation model with autonomous motivation, autonomy support predicting positive affect and goal progress occurred ${ }^{3}$. Both indirect pathways were significant providing evidence for both mediational pathways. Using the model indirect function in MPlus, mediation pathways were determined. Autonomous motivation mediated the relation between autonomy support and increased positive affect over the year $(\mathrm{b}=.008,95 \% \mathrm{CI}=[.002, .013], p$ $=.007)$. Autonomy support mediated the relation between autonomous motivation and increased positive affect over the year $(b=.021,95 \% \mathrm{CI}=[.011, .031], p<.001)$. Autonomous motivation mediated the relation between autonomy support and increased goal progress over the year $(b=$ $.027,95 \% \mathrm{CI}=[.015, .038], p<.001)$. Autonomy support mediated the relation between autonomous motivation and increased goal progress over the year $(\mathrm{b}=.026,95 \% \mathrm{CI}=[.015$,

\footnotetext{
${ }^{3}$ Multiple mediation pathways were significant, and these can be seen in Appendix C on OSF under the output for these analyses.
} 
$.038], p<.001)$. Evidence for this model suggests that the relation between personal and interpersonal autonomy can create an upward spiral or cascade of autonomy, goal progress, and positive affect ${ }^{4}$. As post-hoc analysis, this model was run while controlling for variability in motivation across goals, by using the standard deviation of goal motivation as a control variable. The model still held, and variability significantly predicted autonomy support at T2 and positive affect over the year. To see this output please see Appendix D on OSF.

\footnotetext{
${ }^{4}$ Additionally, a full SEM model with latent variable was run, but had poor fit. A more detailed explanation of this model, as well as the syntax and output can be found in Appendix D on OSF.
} 


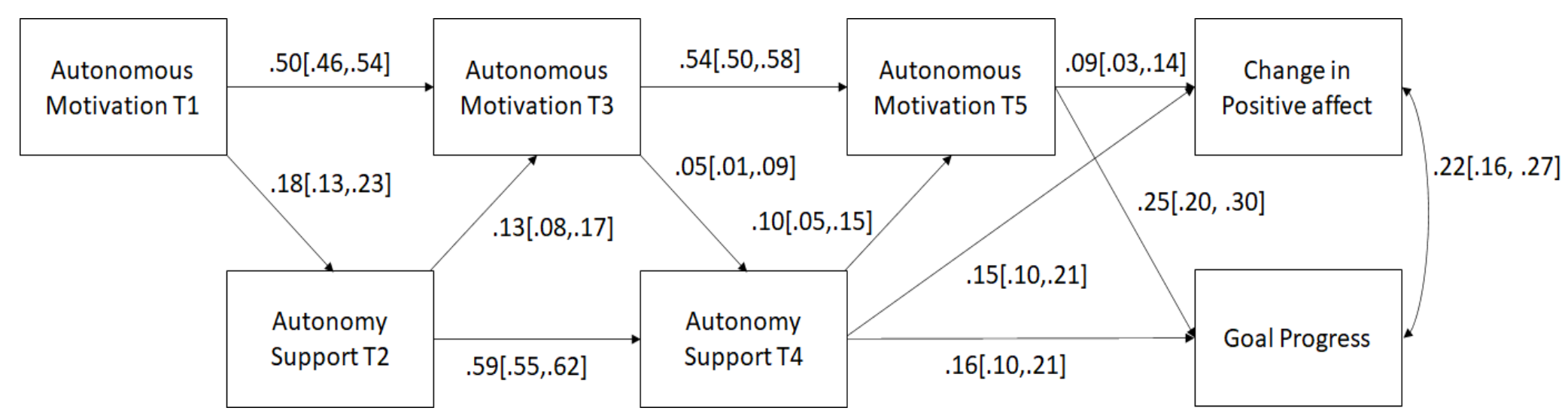

Figure 2. The path model for the reciprocal relation between autonomous support and autonomous motivation and the influence on change in positive affect and goal progress over the year. STDYX standardized values are reported. 


\section{Discussion}

Setting personal goals in emerging adulthood is a normative experience that can facilitate growth and personal success (Koestner et al., 2008, 2020). Although goal setting in emerging adulthood is often considered a claiming of one's independence, the current research suggests that setting autonomous goals is a process that flourishes through collaboration with environments where one perceives their autonomy to be supported. The current research used multiple assessments over the course of a year in a large sample to provide evidence that not only does autonomy support relate to increases in autonomous goal motivation over time, but that the reciprocal relation also exists. Individuals who pursue their goals for autonomous reasons are more likely to report perceiving greater autonomy support over the course of the school year than those who pursue their goals for less autonomous reasons. Additionally, this reciprocal relation builds over time, such that autonomous motivation and perceived autonomy support contribute to one another in an upward spiral. This circular relation results in better goal progress, as well as, gains in positive affect that one experiences while acting and experiencing autonomous goal pursuit. Many students set goals at the beginning of the school year; the current research suggests that students who whole-heartedly endorse their goals, while surrounding themselves with individuals who support their volition, will flourish through gains in motivation, support, progress, and positive affect.

Although autonomy is not a synonym for independence, it is often considered a highly personal form of motivation. The current research finds evidence for the opposite assertion. The development of autonomous motivation flourishes within openly cooperative and satisfying interpersonal environments. Additionally, autonomy supportive environments are fueled by individuals who pursue their goals with whole-hearted volition. The influence of autonomy 
support on autonomous motivation has been well-documented within the literature (see Su \& Reeves, 2011 or Vansteenkiste et al., 2012, for reviews). However, to our knowledge there is limited empirical evidence which finds that autonomous individuals can influence the type of support they receive. The current research suggests that autonomous individuals elicit, or perhaps pursue more autonomy supportive environments.

Although this has not yet been tested within a self-determination theory framework, personality theories often suggest that individuals will either select or manipulate their environments to suit their disposition (Caplan, 1987; McAdams, 2015). The current research broadens the implications of personality-environment fit, by suggesting that perhaps motivationenvironment fit may also be important for an individual's flourishing. Selecting the proper environment to pursue one's goals may facilitate growth in motivation, support, and progress (Roberts et al., 2008). It is easy to imagine that an autonomous student in a controlling environment may have their volition quashed, and this may lead them to change environments. Or, an autonomously motivated student within a controlling environment may work harder to exercise their volition, then the student may be able to manipulate the environment to be more autonomy supportive. When an individual volitionally and wholeheartedly pursues a goal, they may increase their likelihood of eliciting open understanding and support. If someone shares their goals with enthusiasm, interest, and volition, a controlling response would be incongruent. Autonomously motivated individuals may act as the agent of change in their own lives to gain these more autonomy supportive environments. More research is needed to determine the mechanism through which autonomous individuals gain autonomy support from others.

The upward spiral of autonomy suggests that both autonomous motivation and autonomy support continuously contribute to the growth of each other over time, and that this autonomy 
spiral is fueled by gains in positive emotions. The upward spiral of autonomy might be consistent with the broaden and build theory, which suggests that positive emotions lead to a broadening of one's thought-action repertoires, which over time leads to a building of one's skills and resources (Fredrickson, 2001). Positive emotions experienced while acting autonomously or receiving autonomy support may be reinforcing and lead one to continue to pursue autonomous action or autonomy support from others which further fuels gain in positive emotions. Both autonomous motivation and autonomy support are related to need satisfaction and well-being (e.g. Kelly et al., 2015; Gagne, 2003; Sheldon \& Elliot, 1999). Additionally, our findings suggest that those lower in autonomous motivation may receive lower quality support and this may result in less positive affect over time. Further research is needed to explore how someone can break this downward spiral and engage in more personally and interpersonally satisfying goal pursuit. Our current model may suggest that either pathway, an individual identifying with their goals more autonomously or a more enriching support environment, would lead to growth in personal and interpersonal autonomy. Additionally, each incremental increase in either personal or interpersonal autonomy is predicted to lead to this reciprocal upward spiral and well-being over time. Future research is needed to see how a two-pronged approach promoting autonomous motivation and autonomy support could be implemented to help facilitate successful goal pursuit.

\section{Limitations \& Future Directions}

There are a number of limitations to consider within the current research. First, this research was conducted with a university sample, and more research is needed to determine whether this phenomenon extends beyond young adulthood. However, this may also be a strength of this research, as young adulthood is a time when many people make career decisions, 
search for their identity, and achieve independence from parents (Salmela-Aro, 2010). It is a relevant period to test the collaborative nature of autonomy, as young adulthood is one of the most volitional life stages, and when many people set crucial life goals (Shulman \& Nurmi, 2010). Young adulthood is a time when many individuals proclaim their independence, so it is perhaps especially convincing that during young adulthood cooperation and collaboration with others is especially relevant for growth in autonomous motivation, support, and well-being. Further research is needed to determine whether autonomy flourishes as a collaborative process throughout the life span.

Second, the current research aggregated across all types of goals rather than searching for distinct patterns for, say, social versus achievement goals. This allows these findings to be more generalizable, but it also limits the specificity of what we can claim about the development of collaborative autonomy. Further research is needed to determine how broadly applicable this process might be for a variety of goals, or beyond goals for an individual's general autonomous motivation and daily perceived support across different situations. Additionally, we only examined autonomous goal motivation, and not controlled goal motivation. Self-determination theory posits that individuals pursue goals for reasons ranging from more controlled (to avoid punishment or gain approval from others) to more autonomous (for personal enjoyment and fulfillment). More research is needed to see how controlled motivation may influence the type of support an individual receives and if that can influence their motivation.

Third, this research only examined self-reported motivation, support, and affect. Selfreport may not be completely accurate but is commonly used in social science research and has been found to be relatively accurate (e.g. Chan, 2009; Koestner et al., 2002). Moving forward, this research would be strengthened by adding either peer reports, or other more objective 
measures of support, like video taping dyad interactions. Additionally, the current research used a path model, which is not as precise or can have more measurement error than SEM models. We tried to run an SEM, but it had poor fit due to the unequal weighting of the response in the latent variables, which we felt was not an accurate test of our current hypothesis. This supplemental analysis is included in Appendix D on OSF. Finally, the majority of this sample was female, Caucasian and of a relatively high socio-economic status. Future research is needed to determine whether this phenomenon generalizes across more diverse populations. Not every individual may have the luxury of pursuing their passions or goals solely for autonomous reasons due to economic or circumstantial reasons. It would be interesting to see whether these findings would generalize in a sample of emerging adults who decided to not attend university.

Autonomous motivation is associated with perceiving more autonomy support from others. We expect that this might occur because people are seeking out situations that provide them more autonomy. Our research provides preliminary evidence that autonomous goal motivation and perceived autonomy goal support influence each other in a cyclical manner, but how does this cycle start, and is it possible to jump start this upward spiral of autonomy? First, this research would need to be replicated across different samples, and then more research is needed to see whether this cycle could be intervened upon. Of course, this research requires replication across diverse samples, and experimental designs are required to test whether this cycle is subject to intervention. Prior research suggests that when someone is in crisis, they may need more directive or active support from others to help them (Feeney \& Collins, 2015). When an individual is looking for growth related support, a more autonomy supportive form of support may be more appropriate. For example, if an individual is in trouble, giving them positive guidance or solving their problems might be necessary. When an individual whole-heartedly 
endorses a volitional goal, just listening and being open to them may be the more apt response. Additionally, when one is volitional, they might be prouder of their goals, or more likely to tell more family, and friends, or to enlist more supporters. Maybe more autonomous individuals are better at choosing autonomy supportive facilitators, or autonomy supportive situations.

Conversely, perhaps over time our regular supporters learn the most effective style of support across similar situations. For example, an autonomously motivated student in class might consistently need fewer controlling instructions over time and receive more autonomy support from this source. Perhaps, autonomous motivation elicits more autonomy support from others, as autonomy support is the most congruent response when working with an autonomous individual. Alternatively, it may also be that more autonomous individuals are just more open to this form of support, or that they perceive support differently. When you volitionally and wholeheartedly pursue a goal, all support, however passive, might be perceived in a positive manner, or as support for your ambitions. Further research is needed to determine how others respond to more autonomously motivated individuals and how individuals higher in autonomous motivation elicit this rich source of support.

In the future, research is needed to determine how to facilitate this dynamic growth between personal goal autonomy and interpersonally autonomy supportive environments. The current research suggests that interventions which promote need satisfaction (especially autonomy and relatedness satisfaction) in individuals during goal pursuit may help promote successful goal pursuit. Basic psychological need satisfaction has been shown to be related to many well-being and productivity outcomes, as well as to setting more autonomous goals (e.g. Milyavskaya \& Koestner, 2011; Milyavskaya et al., 2014; Ryan and Deci, 2017; Vansteenkiste, Ryan \& Soenens, 2020). There are many interventions that have been shown to be effective at 
facilitating need supportive behaviour (Teixeira et al., 2019). An intervention focused on teaching goal supporters to act in a need satisfying way might be most effective for facilitating goal pursuit. For example, teaching supporters how to encourage open sharing of goals, or how to use non-controlling language while helping support someone's goal pursuit would likely facilitate the goal pursuers autonomy (Teixeira et al., 2019). Many individuals in emerging adulthood rely on their parents during goal pursuit (Koestner, Powers, Holding, Hope \& Milyavskaya, 2020), so targeting this intervention to parents might be especially effective for encouraging autonomy during emerging adulthood.

\section{Conclusion}

The development of autonomous personal goals in young adulthood appears to be a collaborative process fueled by the synergy of autonomous goal motivation and autonomy supportive interpersonal goal environments. Not only does autonomy support lead to increases in autonomous motivation, but autonomous motivation leads to increases in perceived autonomy support. The latter relation has yet to be tested within the self-determination theory literature or within the broader goal and support literature. Pursing personal goals in an autonomous manner can set someone up to experience an upward spiral of autonomous goal motivation, autonomy support, goal progress, and positive emotions. Future research is needed to determine how more autonomously motivated individuals elicit or select more autonomy supportive environments and whether the collaborative personal and interpersonal autonomy spiral can be applied across contexts. 


\section{References}

Bao, X. H., \& Lam, S. F. (2008). Who makes the choice? Rethinking the role of autonomy and relatedness in Chinese children's motivation. Child development, 79, 269-283.

Black, A. E., \& Deci, E. L. (2000). The effects of instructors' autonomy support and students' autonomous motivation on learning organic chemistry: A self-determination theory perspective. Science education, 84, 740-756.

Caplan, R. D. (1987). Person-environment fit theory and organizations: Commensurate dimensions, time perspectives, and mechanisms. Journal of Vocational behavior, 31, 248-267.

Chan, D. (2009). So why ask me? Are self-report data really that bad. Statistical and methodological myths and urban legends: Doctrine, verity and fable in the organizational and social sciences, 309-336.

Emmons, R. A. (1992). Abstract versus concrete goals: personal striving level, physical illness, and psychological well-being. Journal of personality and social psychology, 62, 292.

Feeney, B. C., \& Collins, N. L. (2015). A new look at social support: A theoretical perspective on thriving through relationships. Personality and Social Psychology Review, 19, 113147.

Fitzsimons, G. M., \& Finkel, E. J. (2018). Transactive-Goal-Dynamics Theory: A DisciplineWide Perspective. Current Directions in Psychological Science, 27, 332-338.

Fredrickson, B. L. (2001). The role of positive emotions in positive psychology: The broadenand-build theory of positive emotions. American psychologist, 56, 218 
Gagne, M. (2003). Autonomy support and need satisfaction in the motivation and well-being of gymnasts. Journal of applied sport psychology, 15, 372-390.

Gaudreau, P., Carraro, N., \& Miranda, D. (2012). From goal motivation to goal progress: the mediating role of coping in the Self-Concordance Model. Anxiety, Stress \& Coping, 25, 507-528.

Gorin, A. A., Powers, T. A., Koestner, R., Wing, R. R., \& Raynor, H. A. (2014). Autonomy support, self-regulation, and weight loss. Health Psychology, 33, 332.

Grolnick, W. S., Raftery-Helmer, J. N., Marbell, K. N., Flamm, E. S., Cardemil, E. V., \& Sanchez, M. (2014). Parental provision of structure: Implementation and correlates in three domains. Merrill-Palmer Quarterly (1982-), 60, 355-384.

Hart, J. W., Stasson, M. F., Mahoney, J. M., \& Story, P. (2007). The Big Five and Achievement Motivation: Exploring the Relationship Between Personality and a Two-Factor Model of Motivation. Individual Differences Research, 5.

Holding, A. C., Hope, N. H., Harvey, B., Marion Jetten, A. S., \& Koestner, R. (2017). Stuck in limbo: Motivational antecedents and consequences of experiencing action crises in personal goal pursuit. Journal of Personality, 85, 893-905.

Kelly, R. E., Mansell, W., \& Wood, A. M. (2015). Goal conflict and well-being: A review and hierarchical model of goal conflict, ambivalence, self-discrepancy and selfconcordance. Personality and Individual Differences, 85, 212-229. 
Koestner, R., Powers, T. A., Holding, A., Hope, N., \& Milyavskaya, M. (2020). The relation of parental support of emerging adults' goals to well-being over time: The mediating roles of goal progress and autonomy need satisfaction. Motivation Science.

Koestner, R., Lekes, N., Powers, T. A., \& Chicoine, E. (2002). Attaining personal goals: selfconcordance plus implementation intentions equals success. Journal of personality and social psychology, 83, 231.

Koestner, R., Otis, N., Powers, T. A., Pelletier, L., \& Gagnon, H. (2008). Autonomous motivation, controlled motivation, and goal progress. Journal of personality, 76, 12011230.

Koestner, R., Powers, T. A., Carbonneau, N., Milyavskaya, M., \& Chua, S. N. (2012). Distinguishing autonomous and directive forms of goal support: Their effects on goal progress, relationship quality, and subjective well-being. Personality and Social Psychology Bulletin, 38, 1609-1620.

Koestner, R., Ryan, R. M., Bernieri, F., \& Holt, K. (1984). Setting limits on children's behavior: The differential effects of controlling vs. informational styles on intrinsic motivation and creativity. Journal of personality, 52, 233-248.

McAdams, D. P. (2015). The art and science of personality development. Guilford Publications.

Milyavskaya, M., Inzlicht, M., Hope, N., \& Koestner, R. (2015). Saying “no” to temptation: Want-to motivation improves self-regulation by reducing temptation rather than by increasing self-control. Journal of Personality and Social Psychology, 109, 677. 
Milyavskaya, M., Nadolny, D., \& Koestner, R. (2014). Where do self-concordant goals come from? The role of domain-specific psychological need satisfaction. Personality and Social Psychology Bulletin, 40, 700-711.

Milyavskaya, M., \& Koestner, R. (2011). Psychological needs, motivation, and well-being: A test of self-determination theory across multiple domains. Personality and individual differences, 50, 387-391.

Moreau, E., \& Mageau, G. A. (2012). The importance of perceived autonomy support for the psychological health and work satisfaction of health professionals: Not only supervisors count, colleagues too! Motivation and Emotion, 36, 268-286.

Muthén, L. K., \& Muthén, B. O. (2015). Mplus user's guide (1998-2015). Muthén \& Muthén: Los Angeles, CA.

Patall, E. A., Steingut, R. R., Vasquez, A. C., Trimble, S. S., Pituch, K. A., \& Freeman, J. L. (2018). Daily autonomy supporting or thwarting and students' motivation and engagement in the high school science classroom. Journal of Educational Psychology, 110, 269.

Roberts, B. W., Wood, D., \& Caspi, A. (2008). The development of personality traits in adulthood. Handbook of personality: Theory and research, 3, 375-398.

Ryan, R. M., \& Deci, E. L. (2000). Self-determination theory and the facilitation of intrinsic motivation, social development, and well-being. American psychologist, 55, 68.

Ryan, R. M., \& Deci, E. L. (2017). Self-determination theory: Basic psychological needs in motivation, development, and wellness. Guilford Publications. 
Salmela-Aro, K. (2010). Personal goals and well-being: How do young people navigate their lives? New directions for child and adolescent development, 2010, 13-26.

Shulman, S., \& Nurmi, J. E. (2010). Understanding emerging adulthood from a goal-setting perspective. New directions for child and adolescent development, 2010, 1-11.

Sheldon, K. M. (2014). Becoming oneself: The central role of self-concordant goal selection. Personality and Social Psychology Review, 18, 349-365.

Sheldon, K. M., \& Elliot, A. J. (1999). Goal striving, need satisfaction, and longitudinal wellbeing: the self-concordance model. Journal of personality and social psychology, 76, 482.

Sheldon, K. M., \& Houser-Marko, L. (2001). Self-concordance, goal attainment, and the pursuit of happiness: Can there be an upward spiral? Journal of personality and social psychology, 80, 152.

Sheldon, K. M., \& Kasser, T. (1998). Pursuing personal goals: Skills enable progress, but not all progress is beneficial. Personality and social psychology bulletin, 24, 1319-1331.

Sieber, V., Flückiger, L., Mata, J., Bernecker, K., \& Job, V. (2019). Autonomous goal striving promotes a nonlimited theory about willpower. Personality and Social Psychology Bulletin, 0146167218820921.

Smith, A., Ntoumanis, N., \& Duda, J. (2007). Goal striving, goal attainment, and well-being: Adapting and testing the self-concordance model in sport. Journal of Sport and Exercise Psychology, 29, 763-782. 
Soenens, B., \& Vansteenkiste, M. (2005). Antecedents and outcomes of self-determination in 3 life domains: The role of parents' and teachers' autonomy support. Journal of Youth and Adolescence, 34, 589-604.

Su, Y. L., \& Reeve, J. (2011). A meta-analysis of the effectiveness of intervention programs designed to support autonomy. Educational Psychology Review, 23, 159-188.

Teixeira, P. J., Marques, M. M., Silva, M. N., Brunet, J., Duda, J., Haerens, L., \& Hagger, M. S. (2019). Classification of techniques used in self-determination theory-based interventions in health contexts: An expert consensus study. PsyArXiv, doi: https://doi. org/10.31234/osf. io/z9wqu.

Vansteenkiste, M., Sierens, E., Goossens, L., Soenens, B., Dochy, F., Mouratidis, A., ... \& Beyers, W. (2012). Identifying configurations of perceived teacher autonomy support and structure: Associations with self-regulated learning, motivation and problem behavior. Learning and instruction, 22, 431-439.

Vansteenkiste, M., Simons, J., Lens, W., Sheldon, K. M., \& Deci, E. L. (2004). Motivating learning, performance, and persistence: the synergistic effects of intrinsic goal contents and autonomy-supportive contexts. Journal of personality and social psychology, 87, 246.

Werner, K. M., Milyavskaya, M., Foxen-Craft, E., \& Koestner, R. (2016). Some goals just feel easier: Self-concordance leads to goal progress through subjective ease, not effort. Personality and Individual Differences, 96, 237-242.

Zumbo, B. D. (1999). The simple difference score as an inherently poor measure of change: Some reality, much mythology. Advances in social science methodology, 5, 269-304. 